\title{
Additional copies of the actII regulatory gene induce actinorhodin production in pleiotropic bld mutants of Streptomyces coelicolor A3(2)
}

\author{
Rosa Passantino, ${ }^{1}$ Anna-Maria Puglia ${ }^{1}$ and Keith Chater ${ }^{2 *}$ \\ ${ }^{1}$ Dipartimento di Biologia Cellulare e dello Sviluppo, Università di Palermo, Via Archirafi 22, 010123 Palermo, Italy \\ ${ }^{2}$ John Innes Institute, John Innes Centre for Plant Science Research, Colney Lane, Norwich, NR4 7UH, UK
}

(Received 14 February 1991; revised 10 May 1991; accepted 21 May 1991)

\begin{abstract}
In S. coelicolor there are mutants (named bld) which fail to form aerial mycelium and which are also pleiotropically blocked for synthesis of several antibiotics, including the blue compound actinorhodin. Using a high copy-number vector, a DNA fragment was cloned which restored actinorhodin production, but not aerial mycelium formation, to $b l d A, D, F, G$ and $H$ mutants. Subcloning and Southern blotting revealed that the fragment was from the region (act II) that regulates actinorhodin biosynthesis. The ability to elicit actinorhodin production and to complement an act II mutant was localized to a $1.3 \mathrm{~kb}$ fragment. These results indicate that the structural genes for actinorhodin

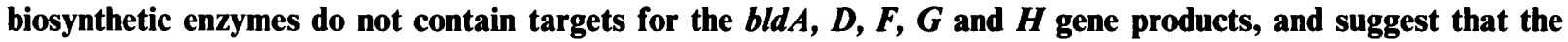
corresponding bld genes control actinorhodin synthesis principally via a single gene in the act II regulatory region.
\end{abstract}

\section{Introduction}

In Streptomyces coelicolor A3(2), genetic approaches have been used extensively to analyse the regulation of morphological and physiological differentiation (the formation of a sporulating aerial mycelium and the synthesis of secondary metabolites, respectively). These two processes both take place after the period of most rapid vegetative growth. This temporal coincidence at least partially reflects common regulatory elements, since five classes of mutants (bld $A, B, D, G$ and $H$ ) have been described that - on the normally used laboratory media - are simultaneously deficient in aerial mycelium formation and the synthesis of several distinct antibiotics, including the blue-coloured actinorhodin and the red undecylprodigiosin (Merrick, 1976; Champness, 1988). Although the molecular nature of most of these bld gene products is unknown, it has been shown that one of the genes, bldA, specifies the leucyl tRNA for the rare UUA codon (Lawlor et al., 1987; Leskiw et al., 1991). In addition, two laboratories have isolated bld mutants that produce undecylprodigiosin but not actinorhodin, (bldE: Hodgson, 1980; bldF: Puglia et al., 1986). The work described here was initiated by attempts to clone $b l d F$, but went on to incorporate experiments with four of the other relatively well characterized mutant classes; bldA, $D, G$ and $H$. The fifth well characterized class, bld $B$, was not analysed because it produces spores and actinorhodin on prolonged incubation. In this study, a DNA fragment cloned from $S$. coelicolor is shown to be capable of restoring actinorhodin production - but not sporulation - to representative mutants of the five classes. The cloned fragment is shown to correspond to actII-ORF4, a positive regulatory gene located among, and apparently controlling most or all of, the clustered genes for actinorhodin biosynthesis (Rudd \& Hopwood, 1979; Malpartida \& Hopwood, 1986; Fernández-Moreno, et al., 1991). These results may help to unravel the apparently complex regulatory network in which the bld genes participate.

\section{Methods}

Bacterial strains. The mutant strains (Table 1) were derived from the wild-type $S$. coelicolor A3(2) (Hopwood et al., 1985a). S. lividans 66 (John Innes Institute strain 1326; Hopwood et al., 1985a) was used as cloning host and for phage propagation. Escherichia coli JM101 (supE thi $\Delta\left(\right.$ lac-proAB) $\left[\mathrm{F}^{\prime}\right.$, traD36 proAB lac ${ }^{\natural}$ lacZ $\left.\triangle M 15\right]$ (Messing et al., 1981) was used as plasmid host.

Plasmids and phages. High copy number Streptomyces plasmid vectors were pIJ702 (Katz et al., 1983) and pIJ699 (Kieser \& Melton, 1988). pIJ2925 [a pUC18 (Yanisch-Perron et al., 1985) derivative with a modified polylinker flanked by $B g l$ II sites: G. H. Janssen, personal communication] was provided by $\mathbf{M}$. J. Bibb. pIJ2323 and pIJ2327 [pBR325 derivatives containing segments of DNA extending from sites 2-11 and 10-13, respectively, of the act restriction map of Malpartida \& Hopwood (1986)] were constructed by F. Malpartida and provided by D. A. Hopwood. Plasmid pUC19 (Yanisch-Perron et al., 1985) was 
Table 1. S. coelicolor strains

\begin{tabular}{|c|c|c|c|}
\hline Strain & Genotype & Plasmid status & Source or Reference \\
\hline $\begin{array}{l}\text { M145 } \\
\text { JF2 } \\
\text { J1700 } \\
\text { J774 } \\
\text { (w)C103* } \\
\text { (w)C109* } \\
166 \dagger\end{array}$ & $\begin{array}{l}\text { Prototroph } \\
\text { argAl guaAl actIII05 red B52 } \\
\text { hisAl uraAl strAl pgl- bldA } 39 \\
\text { cysA15 pheA1 mthB2 bldD53 } \\
\text { hisAl uraAl strAl pgl- bldG103 } \\
\text { hisAl uraAl strAl pgl- bldH109 } \\
\text { hisD3 pheAl strAl bldF }\end{array}$ & $\begin{array}{l}\text { SCP1- SCP2- } \\
\text { SCP1- SCP2 } \\
\text { SCP1- SCP2- } \\
\text { SCP1 } 2^{-} \text {SCP2 } 2^{+} \\
\text {SCP1- SCP2- } \\
\text { SCP1- SCP2- } \\
\text { SCP1 } 2^{-} \text {SCP2 }\end{array}$ & $\begin{array}{l}\text { M. J. Bibb } \\
\text { Feitelson \& Hopwood (1983) } \\
\text { Lawlor et al. (1987) } \\
\text { Merrick (1976) } \\
\text { Champness (1988) } \\
\text { Champness (1988) } \\
\text { A.-M.Puglia and coworkers } \\
\text { (unpublished) }\end{array}$ \\
\hline
\end{tabular}

* These strain designations have been prefixed with $(w)$ to avoid confusion with previously described $S$. coelicolor strains with C designations (Hopwood et al., 1970; Chater, 1972).

$\dagger$ University of Palermo strain collection number.

purchased from Pharmacia. KC304, a derivative of the Streptomyces temperate phage $\phi \mathrm{C} 31$ previously described by Hopwood et al. (1987), was used in the subcloning.

Culture conditions, transformation and transfection procedures. Streptomyces strains were grown in liquid YEME medium supplemented with $34 \%(\mathrm{w} / \mathrm{v})$ sucrose, $5 \mathrm{mM}-\mathrm{MgCl}_{2}$ and auxotrophic requirements of the individual strains, or on solid medium R2YE (Hopwood et al., 1985a). Protoplasting, transformation and transfection of $S$. lividans and $S$. coelicolor strains were as in Hopwood et al. (1985a). E. coli JM101 was grown and transformed by standard procedures (Maniatis et al., 1982).

Transduction. Phage suspensions were mixed with spores or mycelial fragments of the recipient strain directly on R2YE agar plates. After incubation at $30^{\circ} \mathrm{C}$ for $6 \mathrm{~d}$, the growth was replicated onto medium containing thiostrepton $\left(50 \mu \mathrm{g} \mathrm{ml}^{-1}\right)$ to select for transductants.

DNA procedures. Chromosomal, plasmid and bacteriophage DNA were isolated as in Hopwood et al. (1985a). For shotgun cloning, DNA from strain M145 was partially digested with Sau3AI and sizefractionated on a sucrose gradient (Hopwood et al., 1985a). Fragments in the $5 \mathrm{~kb}$ to $15 \mathrm{~kb}$ size range were ligated with $\mathrm{Bg} / \mathrm{II}$-digested pIJ702. Southern blotting was as in Hopwood et al. (1985a). Probes were radiolabelled with $\left[\alpha-{ }^{32}\right.$ P $]$ dCTP by using the Multiprime DNA labelling kit (Amersham). Plaque lifts onto Hybond membranes (Amersham) and hybridization were carried out according to the manufacturer's recommendations.

\section{Results}

\section{Cloning of a DNA fragment which restored actinorhodin production to a bldF mutant}

Previous mutagenesis experiments identified a novel mutant (bldF) of $S$. coelicolor (Puglia et al., 1986 and manuscript in preparation). This mutant never forms aerial hyphae and spores under any growth conditions tested, nor does it produce the antibiotics actinorhodin, 'calcium-dependent antibiotic' and methylenomycin. It produces only the mycelium-bound red antibiotic undecylprodigiosin. In an attempt to clone bldF, a genomic library of $S$. coelicolor DNA was constructed in the bldF mutant using the high copy number vector pIJ702. In spite of a high probability of having a complete library, no colonies developing aerial mycelium were observed However, a bald colony producing large amounts of blue pigment (presumed to be actinorhodin) was isolated. The recombinant plasmid (pSCbl-1) extracted from this colony carried a $13 \mathrm{~kb}$ DNA insert. Successive subcloning experiments showed that actinorhodin production could be induced by a fragment of only $1.3 \mathrm{~kb}$, located at one end of the insert (pSCbl-3: Fig. 1). Removal of $0 \cdot 2 \mathrm{~kb}$ from the righthand end of the $1.3 \mathrm{~kb}$ fragment, leaving a $1 \cdot 1 \mathrm{~kb}$ Sst I-BamHI fragment (pIJ69: Fig. 1) eliminated the effect.

\section{Localization and identification of the $1.3 \mathrm{~kb} D N A$ fragment.}

In $S$. coelicolor, actinorhodin synthesis is controlled by the act gene cluster (Rudd \& Hopwood, 1979). Of eight classes of act mutants defined by cosynthesis tests, one (act II), failed to cosynthesize actinorhodin with any other mutants. This class seems to define a positively acting control gene (Rudd \& Hopwood, 1979; Fernández-Moreno et al.). In complementation tests with an act II mutant, JF1, Malpartida \& Hopwood (1986) localized act II to a $\sim 5 \mathrm{~kb}$ section of the act cluster (Fig. 2). The right-hand end of this region has been implicated in the induction of actinorhodin overproduction in $S$. coelicolor and $S$. lividans by certain recombinant plasmids (Hopwood et al., 1985b and D. A. Hopwood and H. M. Kieser, personal communication).

In the course of the analysis of the cloned DNA in pSCbl-1, it became apparent that part of its restriction map resembled that of part of the act cluster. Further detailed restriction map comparison (Fig. 2) showed that pSCbl-1 included $8 \mathrm{~kb}$ that aligned with the act $\mathrm{V}$-act II region, and $5 \mathrm{~kb}$ from elsewhere in the $S$. coelicolor genome. Southern blots with cloned act DNA as probe (i.e. using pIJ2323 and pIJ2327) confirmed the presence of the act $\mathrm{V}$-act II region in pSCbl-1, and showed that the $1.3 \mathrm{~kb}$ smallest fragment eliciting actinorhodin produc- 

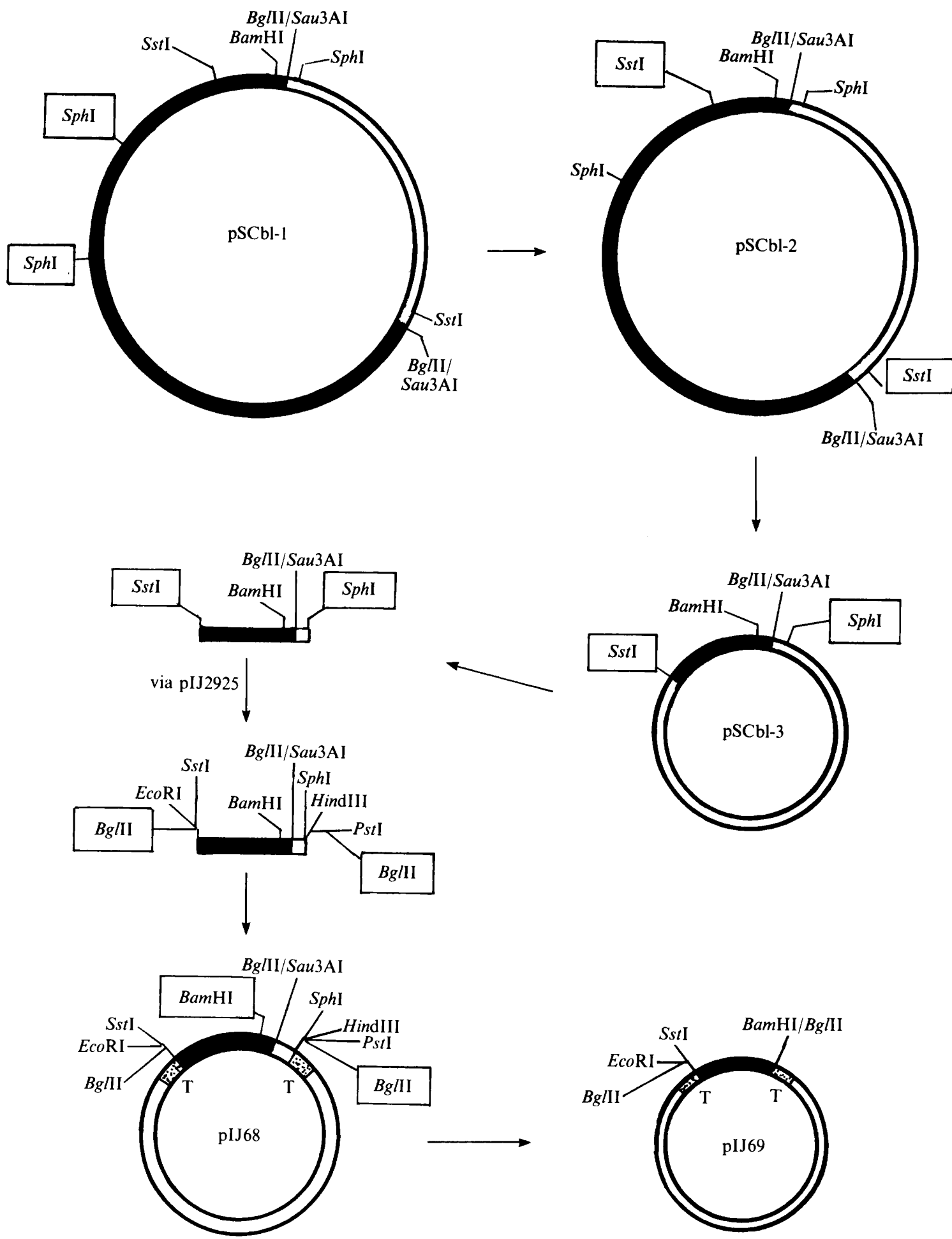

Fig. 1. Construction of plasmids. At each step, the DNA was cut at the sites indicated by boxes, then either self-ligated or ligated with a suitably cut vector. pIJ68 was constructed using BgIII-digested pIJ699 as vector. White segments; vector DNA; black segments, cloned $S$. coelicolor DNA; stippled segments, fd terminator sequences (T) of pIJ699. 
(a) Acetate $\stackrel{\text { I, III }}{\longrightarrow} \stackrel{\text { III }}{\longrightarrow} \stackrel{\text { IV }}{\longrightarrow} \stackrel{\text { VI }}{\longrightarrow} \stackrel{\text { V }}{\longrightarrow}$ Actinorhodin

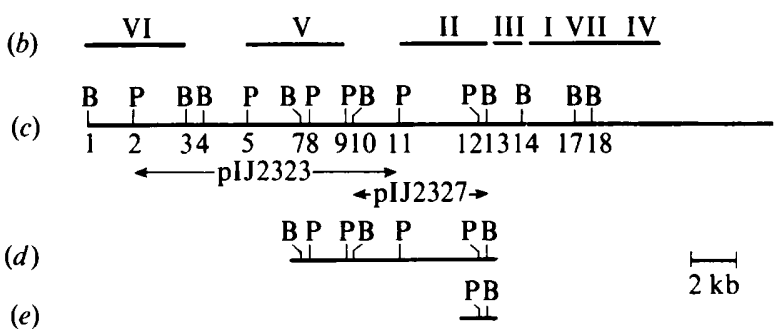

Fig. 2. Localization of the $8 \mathrm{~kb}$ and $1.3 \mathrm{~kb}$ fragments carried by pSCbl1 and $\mathrm{pSCbl}-3$ respectively, within the actinorhodin cluster of $S$. coelicolor. (a) Actinorhodin biosynthetic pathway. (b) Locations of mutant classes (Malpartida \& Hopwood, 1986). (c) Restriction map of the actinorhodin cluster showing coordinates assigned by Malpartida \& Hopwood (1986). (d) Restriction map of an $8 \mathrm{~kb}$ segment from one end of the insert in pSCbl-1. (e) Restriction map of $1.3 \mathrm{~kb}$ fragment capable of eliciting actinorhodin production in bld mutants and in an act II mutant. P, PstI; B, BamHI.

tion in the bldF mutant corresponded to a segment at the right-hand end of the act II region. In confirmation of this, pSCbl-3 restored actinorhodin production to the act II mutant strain JF2. Furthermore, the $1.3 \mathrm{~kb}$ sequence was probably expressed from its own promoter; this was shown by cloning the smaller SphI-SstI fragment of pSCbl-3, via pIJ2925 to modify its ends, between the $B g l I I$ sites of pIJ699, a vector in which transcription terminators prevent readthrough from vector promoters (Kieser \& Melton, 1988) (Fig. 1). Actinorhodin production was obtained when the resulting plasmid, pIJ68, was introduced into the $b l d F$ mutant.

Restoration of actinorhodin synthesis in bldA, D, G and $H$ strains.

Since pIJ68 could cause the bldF mutant to produce actinorhodin, it was of interest to investigate its effect on other representative bld mutants (bldA, $D, H$ and $G$ ). All the strains carrying pIJ68 produced actinorhodin after $2-3 \mathrm{~d}$ growth. To investigate whether just a single extra copy of the $1.3 \mathrm{~kb}$ sequence was able to restore actinorhodin synthesis, phage KC810 was constructed. KC810 carried the same $B g l$ II fragment as described above for pIJ68, ligated between the BamHI sites of vector $\mathrm{KC} 304$. (This vector, derived from $\phi \mathrm{C} 31$, carries the $\phi \mathrm{C} 31$ attP site, and can readily integrate into the $S$. coelicolor chromosomal attB site, to give thiostreptonresistant transductants.) With the exception of the bldF mutant, all the bld strains transduced with KC810 failed to produce actinorhodin. The actinorhodin synthesis in bldF transductants was delayed compared with the high copy number cloning experiments; a low amount of actinorhodin production was detectable only after 7-8 d incubation at $30^{\circ} \mathrm{C}$.

\section{Discussion}

A $1.3 \mathrm{~kb}$ fragment of DNA from the actII region, capable of complementing an actII mutant, could elicit conspicuous actinorhodin production in bldA, $D, F, G$ and $H$ mutants when present at a high copy-number. Other aspects of the pleiotropic bld mutant phenotypes, such as aerial mycelium deficiency and (for bldA, $D, G$ and $H$ ) non-production of the red compound undecylprodigiosin, were not affected. From the DNA sequence of the act II region (Fernández-Moreno et al., 1991) it is clear that this $1.3 \mathrm{~kb}$ fragment contains a single complete coding sequence (act II-ORF4) preceded by an intergenic region and the last $\sim 200 \mathrm{bp}$ of another gene, act IIORF3. The fragment also contains about $130 \mathrm{bp}$ of DNA downstream of act II-ORF4. The simplest interpretation of these results is that the actinorhodin deficiency of each of the five classes of bld mutant is due to a reduction in the active product of the actII-ORF4 regulatory gene. This would be predicted to cause reduced transcription of the act genes specifying the enzymes of actinorhodin biosynthesis. In support of this, a transcriptional fusion of the $x y l E$ reporter gene to the actI transcription unit encoding early steps in the biosynthetic pathway gave strong $x y l E$ expression in $b l d A^{+}$, but not in $b l d A^{-}$, strains (Bruton et al., 1991). Probably, a low level of actII-ORF4 gene product is made in each of the bld mutants tested: thus, increasing the copy number of actII-ORF4 in the bld mutants would cause a proportionate increase in the amount of its gene product up to a level capable of eliciting expression of the act structural genes. (Our results make it unlikely that bld mutants fail to make actinorhodin because they cannot supply a precursor or cofactor for its synthesis: over-expression of actII-ORF4 would not be expected to suppress such a metabolic block.)

The molecular nature of most of the bld genes is still undetermined. However, bldA is known to specify a leucyl tRNA (probably the only one) for the codon UUA, a particularly rare codon in streptomycetes (Lawlor et al., 1987; Leskiw et al., 1991). Among several TTAcontaining genes tested by Leskiw et al. (1991), some were completely unexpressed in bldA mutants (at the level of gross phenotype), whereas others showed partial expression, most probably because of a low level of translation of UUA codons by an unidentified noncognate tRNA. DNA sequencing has shown that actIIORF contains a TTA codon, providing a potential target for bldA action (Fernández-Moreno et al., 1991). Thus, 
our results are compatible with the proposal of Fernández-Moreno et al. (1991), supported in their paper by sitedirected mutagenesis of the TTA codon, that act IIORF4 expression in a bldA mutant is limited at the level of translation of the corresponding UUA codon. Since the effect of increasing actII-ORF4 copy-number appears to be very similar in bldD, $G$ and $H$ mutants to that observed in the bldA mutant, these mutations may also eliminate the active form of the bld $A$-specific tRNA (for example, by interfering with its transcription, processing, modification or charging). On the other hand, actinorhodin production in the bldF mutant is probably affected in a way that gives a less drastic reduction of act II expression. This could result from any of several causes including: reduced transcription of act II ; reduced translation of its mRNA (perhaps by an imperfectly modified bldA gene product); or reduced stability of its protein product. Any satisfactory explanation of the $b l d F$ phenotype must be compatible with the following three features: first, the mutant is a strong producer of undecylprodigiosin; second, even a single extra copy of act II is sufficient to cause production of some actinorhodin (a circumstance that failed to elicit production in the other bld mutants); and third, the morphological defect of the bldF mutant, unlike that of bldA, D, $G$ or $H$ mutants, is not phenotypically revertible by changing the carbon source in minimal medium from glucose to mannitol.

The ability of the act II gene at high copy number to cause strong actinorhodin production in a bldA mutant leads to the expectation that there are either no TTA codons, or none with strong bldA dependence, in the genes encoding the enzymes of actinorhodin synthesis. The same expectation arises from the site-directed mutagenesis experiment of Fernández-Moreno et al. (1991); and available sequence information both in that paper, and from Hallam et al. (1988), J. L. Caballero (personal communication) and Fernández-Moreno (1990) has revealed only one further TTA codon (in a putative actinorhodin export gene: Fernández-Moreno et al. (1991) in more than $14 \mathrm{~kb}$ of act DNA. Undecylprodigiosin synthesis can be switched on under some conditions in bldA mutants, indicating that TTA codons are also absent from all the red genes for biosynthetic enzymes of this pathway (Guthrie \& Chater, 1990). Taken together, these results support the suggestion that the primary translation-level effects of the bldA-specified tRNA on antibiotic synthesis are exerted principally on regulatory genes (Leskiw et al., 1991).

We thank M. Noto, G. Di Marco and A. Polisano for their technical assistance, D. A. Hopwood, B. K. Leskiw and F. Malpartida for helpful comments on the manuscript, and M. A. Fernandez-Moreno and J. L. Caballero for communication of unpublished results. This work was supported in part by grants from the 'Progretto Finalizzato Biotechnologie e Biostrumentazione' of C.N.R. and from the John Innes Foundation; and in part through a grant-in-aid from the Agricultural and Food Research Council to the John Innes Institute.

\section{References}

Bruton, C. J., Guthrie, E. P. \& Chater, K. F. (1991). Phage vectors that allow monitoring of transcription of secondary metabolism genes in Streptomyces. Bio/Technology (in the Press).

ChampNess, W. C. (1988). New loci required for Streptomyces coelicolor morphological and physiological differentiation. Journal of Bacteriology 170, 1168-1174.

CHATER, K. F. (1972). A morphological and genetic mapping study of white colony mutants of Streptomyces coelicolor. Journal of General Microbiology 72, 9-28.

Feitelson, J. S. \& Hopwood, D. A. (1983). Cloning of a Streptomyces gene for an $O$-methyltransferase involved in antibiotic biosynthesis. Molecular and General Genetics 190, 394-398.

FERNÁNDEZ-MORENO, M. A. (1990). Síntesis y regulación de la expresión del antibiótico poliquétido Actinorhodina en Streptomyces coelicolor A3(2). PhD thesis, Universidad Autonoma de Madrid.

Fernández-Moreno, M. A., Caballero, J. L., Hopwood, D. A. \& MALPARTIDA, F. (1991). The actinorhodin gene cluster contains regulatory and antibiotic export genes that are direct targets for translational control by the bldA tRNA gene of Streptomyces coelicolor. Cell (in the Press).

Guthrie, E. P. \& Chater, K. F. (1990). The level of a transcript required for production of a Streptomyces coelicolor antibiotic is conditionally dependent on a tRNA gene. Journal of Bacteriology 172, 6189-6193.

Hallam, S. E., Malpartida, F. \& Hopwood, D. A. (1988). Nucleotide sequence, transcription and deduced function of a gene involved in polyketide antibiotic synthesis in Streptomyces coelicolor. Gene 74, 305-320.

Hodgson, D. A. (1980). Carbohydrate utilization in Streptomyces coelicolor $A 3(2)$. PhD thesis, University of East Anglia.

Hopwood, D. A., Wildermuth, H. \& PALMER, H. M. (1970). Mutants of Streptomyces coelicolor defective in sporulation. Journal of General Microbiology 61, 397-408.

Hopwood, D. A., BibB, M. J., Chater, K. F., Kieser, T., Bruton, C. J., KIESER, H. M., LydiATE, D. J., SMITH, C. P., WARD, J. M. \& SCHREMPF, H. (1985a). Genetic Manipulation of Streptomyces - a Laboratory Manual. Norwich: The John Innes Foundation.

Hopwood, D. A., Chater, K. F. \& Malpartida, F. (1985b). Gene cloning to analyse the organisation and expression of antibiotic biosynthesis genes in Streptomyces. In Regulation of Secondary Metabolite Formation. Proceedings of the XV International Congress of Genetics. Vol. II: Recombinant DNA technology, pp. 22-33. Edited by $H$. Kleinkauf, H. van Dohren, H. Dormauer \& G. Nesseman. Weinheim: VCH.

Hopwood, D. A., BibB, M. J., Chater, K. F. \& Kieser, T. (1987). Plasmid and phage vectors for gene cloning and analysis in Streptomyces. Methods in Enzymology 153, 116-166.

KatZ, E., Thompson, C. J. \& Hopwood, D. A. (1988). Cloning and expression of the tyrosinase gene from Streptomyces antibioticus in Streptomyces lividans. Journal of General Microbiology 129, 27032714.

Kieser, T. \& Melton, R. (1983). Plasmid pIJ699, a multi-copy positive-selection vector for Streptomyces. Gene 65, 83-91.

Lawlor, E. J., Baylis, H. A. \& Chater, K. F. (1987). Pleiotropic morphological and antibiotic deficiencies result from mutations in a gene encoding a tRNA-like product in Streptomyces coelicolor A3(2). Genes \& Development 1, 1305-1310.

Leskiw, B. K., Lawlor, E. J., Fernandez-Abalos, J. M. \& Chater, K. F. (1991). TTA codons in some genes prevent their expression in a class of developmental, antibiotic-negative Streptomyces mutants. Proceedings of the National Academy of Sciences of the United States of America 88, 2461-2465. 
Malpartida, F. \& Hopwood, D. A. (1986). Physical and genetic characterisation of the gene cluster for the antibiotic actinorhodin in Streptomyces coelicolor A3(2). Molecular and General Genetics 250, 66-73.

Maniatis, T., Fritsch, E. F. \& Sambrook, J. (1982). Molecular Cloning: a Laboratory Manual. Cold Spring Harbor, NY: Cold Spring Harbor Laboratory.

MERRICK, M. J. (1976). A morphological and genetic mapping study of bald colony mutants of Streptomyces coelicolor. Journal of General Microbiology 96, 299-315.

MESSING, J. (1981). A system for shotgun DNA sequencing. Nucleic Acids Research 9, 309-321.
Puglia, A.-M., Alberti, M., Bucca, G., Granozzi, C., Passantino, R. \& MisuraCA, F. (1986). Heat shock proteins and differentiation in Streptomyces coelicolor A3(2). In Abstracts of the 5th International Symposium on the Genetics of Industrial Micro-organisms. Split, Yugoslavia.

RudD, B. A. M. \& Hopwood, D. A. (1979). Genetics of actinorhodin biosynthesis by Streptomyces coelicolor A3(2). Journal of General Microbiology 114, 35-43.

Yanisch-PerRon, C., Vieira, J. \& Messing, J. (1985). Improved M13 vectors and host strains: nucleotide sequences of the M13 mp18 and pUC19 vectors. Gene 33, 103-119. 